\title{
Estudio sobre la reforma de la Escuela Superior de Diplomática en 1863 y el nombramiento de Juan Facundo Riaño como catedrático de Historia de las Bellas Artes - Arqueología Monumental - \\ Study on the reform of the Escuela Superior de Diplomática in 1863 and the appointment of Juan Facundo Riaño as Professor of History of Fine Arts - Monumental Archaeology -
}

Ignacio A. Muñoz González ${ }^{1}$

\begin{abstract}
Resumen
Juan Facundo Riaño y Montero (Granada, 1828 - Madrid, 1901) fue una de esas personalidades que huía la publicidad y gustaba de trabajar en la sombra. Profesor, arqueólogo, académico y político, fue responsable de la creación del Museo de Reproducciones Artísticas y tuvo gran peso a la hora de crear el Museo Pedagógico, la Escuela de Institutrices y la Escuela de artes Industriales de Toledo; así como en la reforma de Escuela Central de Maestras y de las Escuelas de Párvulos. Es uno de los pioneros de la metodología arqueológica moderna, influyendo además en la formación de toda una generación de arqueólogos a través de su Cátedra de la Escuela Superior de Diplomática, el primer centro público en impartir Arqueología a nivel universitario en España. La ESD fue reorganizada en 1863, sin que el proceso de reestructuración y nombramiento de nuevos catedráticos haya sido objeto de estudio.
\end{abstract}

Palabras clave: Arqueología, pedagogía, ESD, epistolario, España, s.XIX.

\begin{abstract}
Juan Facundo Riaño y Montero (Granada, 1828 - Madrid, 1901) was one of those personalities who avoided publicity and liked to work in the shade. Professor, archaeologist, academic and political, was responsible for the creation of the Casts Museum of Madrid and had great responsibility in creating the Pedagogical Museum, the Schoolmistress School and the Industrial Arts School of Toledo; as well as in the reform of Teachers Central School and the Nursery School. It is one of the pioneers of modern archaeological methodology, also influencing the formation of a new generation of archaeologists through his Chair at the Escuela Superior de Diplomática, the first public Centre in teaching Archaeology at the college level in Spain. The ESD was reorganized in 1863, while the process of restructuring and appointment of new professors have not been studied yet.
\end{abstract}

Keywords: Archaeology, pedagogy, ESD, epistolary, Spain, $19^{\text {th }}$ century.

\section{INTRODUCCIÓN}

La Escuela Superior de Diplomática fue el primer centro público en impartir Arqueología a nivel universitario en España, su creación se remonta a 1856 cuando, a iniciativa de la Real Academia de la Historia, y siguiendo el modelo francés de la École Nationale des Chartes (Blech, 2002: 92), se crea un centro en el que formar a los profesionales encargados de excavar, investigar, proteger, cus- todiar y conservar los objetos y documentos que pasaron a la propiedad del Estado, tras la desamortización de Juan Mendizábal, de 19 de febrero de 1836.

El proceso se remonta al Decreto de desamortización de los bienes de la Iglesia promulgado por las Cortes de Cádiz el 13 de septiembre de 1813, que fue paralizado por Fernando VII, recuperado durante el Trienio Liberal (1820-1823), de nuevo paralizado por el mismo monarca y recuperado por última vez -ante la casi inmi-

Doctor por la Universidad Autónoma de Madrid. direccionmuseo@ gregorioprieto.org 
nente bancarrota del Estado- el 29 de julio de 1835, ya sin vuelta atrás. La desamortización, además de vender tierras y fincas de la Iglesia, implicaba hacerse cargo de los bienes conservados en las bibliotecas y archivos de los monasterios y conventos afectados, lo que a su vez suponía que estos debían ser catalogados e inventariados por personas competentes, capaces de apreciar las obras de arte, fecharlas y tasarlas; para esto, además de una sólida cultura y formación en artes y profesiones afines, era muchas veces necesario leer con facilidad el latín y ser capaz de entender las abreviaturas más utilizadas, y no pocas veces entender el griego o el árabe. Los Gobernadores (Jefes Políticos) de cada región debían ayudarse para la tarea de aquellos con las capacidades requeridas, designándose las comisiones entre los miembros de las Reales Academias de la Historia y Bellas Artes y equivalentes provinciales, Reales Sociedades de Amigos del País, trabajadores de archivos, etc.; ante la ingente labor que se tenía por delante, pronto las Academias se dieron cuenta de que España adolecía de los profesionales con formación necesarios para, no sólo llevar a cabo la tarea, sino prolongarla en el tiempo y ordenar los bienes de manera adecuada y con garantías de conservación, lo cual estaba provocando que el proceso se desarrollase lentamente y los bienes fueran vendidos en el extranjero ilegalmente (Almagro Gorbea, 2002: 55).

En mayo de 1837 se reguló la composición de las comisiones que debían catalogar los bienes, en la forma jurídica de Juntas Cientifico-Artísticas, las cuales debían estar compuestas por cinco personas con formación, y presididas por el Jefe Político; ante el evidente fracaso estas se reorganizaron, en junio de 1844, en las Comisiones Provinciales de Monumentos Históricos y Artísticos, dependientes en principio de la Real Academia de Bellas Artes de San Fernando, pero coordinadas por la Comisión Central, que estaba formada por un presidente -el Ministro de Gobernación-, un vicepresidente y un secretario, además de 5 vocales (Mederos, 2010: 166). La Comisión Central de Monumentos Históricos y Artísticos fue suprimida en la Ley de 9 de septiembre de 1857 -ley que volverá a aparecer en este artículo más adelante- volviendo a encargarse la Real Academia de Bellas Artes de San Fernando de la coordinación de los trabajos, y pasando finalmente dichas atribuciones a la Comisión Mixta de las Reales Academias de la Historia y de Bellas Artes de San Fernando, en julio de 1864. Juan Facundo Riaño, como miembro de las dos academias, formó más adelante parte de dicha comisión, que estaba compuesta por tres Académicos de la Real Academia de la Historia y dos de la Real Academia de Bellas Artes de San Fernando.

No obstante, las Academias no daban abasto y el proceso de catalogar los documentos se alargaba en el tiempo, sin paleógrafos capaces de afrontar la ingente tarea, a esto se suma el que la Real Academia de la Historia estaba compuesta por pocos miembros, y estos ya mayores; mediante el Real Decreto de 25 de febrero de 1847 se estableció el número de Individuos de dicha Academia en 36, facilitando así la incorporación de jóvenes académicos -entre los treinta y pocos y los cuarenta años- capaces de viajar por toda España en fatigosas jornadas de diligencia o caballo, cuando no mulo o burro, como los famosos viajes de Pascual de Gayangos (Álvarez, 2007). Precisamente a raíz de un viaje de Pascual de Gayangos a Portugal, donde visitó la Escuela de Diplomática allí existente, se inició en la Real Academia de la Historia -el 22 de octubre de 1852- la solicitud para crear una institución análoga en España, aunque no se aprobaría hasta el 29 de agosto de 1856 (Maier, 2008a: 53), plasmándose en el Real Decreto de 7 de octubre de 1856. El 17 de julio de 1858 se creó Cuerpo Facultativo de Archiveros y Bibliotecarios, encargado de conservar y exponer correctamente los documentos y artísticos y arqueológicos en los archivos, bibliotecas y museos del país; en abril de 1867 los profesores de la Escuela Superior de Diplomática serían incorporados al Cuerpo de Archiveros, Bibliotecarios y Anticuarios, quedando establecida la Escuela como la encargada de otorgar el título de dicho Cuerpo.

Antes de la creación de la Escuela Superior de Diplomática, se podían adquirir conocimientos de arqueología en la Cátedra de Arqueología del Ateneo de Madrid, la de Numismática en el Liceo Artístico y Literario de Madrid, y en la Sociedad Económica Matritense, a través de la cátedra de Paleografía -que fue incorporada a la Escuela, por el Real Decreto de 1856, junto con el profesor que la impartía, Juan de Tró y Ortolano- además de en algún centro provincial análogo; con la creación de la Escuela Superior de Diplomática se regulaban los estudios, que pasaron a ser superiores en 1857 , y se concentraba su enseñanza -independientemente de que siguiesen existiendo las cátedras privadas- en un solo edificio: en la Biblioteca de la Real Academia de la Historia, primero, y en los Reales Estudios de San Isidro más adelante, para acabar en el edificio de la Universidad Central (Godín, 1995: 47-48).

\section{Arqueología Monumental}

La asignatura Historia de las Bellas Artes en los tiempos antiguos, Edad Media y Renacimiento se creó en la Escuela Superior de Diplomática, adscrita a la Universidad Central, justo un día antes del nombramiento de Juan Facundo Riaño como catedrático - merced a la ampliación de las competencias de la Escuela- tras el Real Decreto de 15 de julio de 1863, siendo la única en Madrid en la que se estudiaba la Historia del Arte a ese nivel (Gómez, 2007); esta asignatura -de Arqueología Monumental, también llamada Artística o Arquitectónica- trataba de la historia de la arqueología, y de la catalogación e inventariado de bienes artísticos y arqueológicos, si bien estaba orientada, como todos los estudios de la Escuela, hacia la conservación y catalogación de las colecciones de los museos, más que a la arqueología tal y como la entendemos hoy en día (Maier, 2008b, 179).

Arqueología Monumental es un concepto con el que actualmente no estamos tan familiarizados como en el 
s.XIX, cuando era la rama más común de la arqueología, y la prehistoria y paleontología eran casi completamente desconocidas; aún cuando parece que ya en 1735 se celebró en París un Congreso de Estudios Prehistóricos (Macarrón y González, 2007: 19), no fue sino hasta 1859 en que la Sociedad Geológica de Londres reconoció que los útiles de sílex eran obra del hombre. Al margen de la prehistoria, la Arqueología Monumental surge de la corriente romántica y neogótica de la primera mitad de siglo, cuando los intelectuales y las autoridades empezaron a valorar formas artísticas diferentes a las de Grecia y Roma, y a ampliar su concepto de monumento más allá de los órdenes clásicos; al calor de esta recuperación del interés por los monumentos arquitectónicos nacionales, surgen dos corrientes primordiales de enfrentarse a una antigüedad: la que proponía devolverle su antiguo esplendor reconstruyéndola tal y como fue proyectada-liderada por Viollet-le-Duc desde su entrada, en 1845, en la Comisión de Monumentos francesa-, y la que abogaba por estudiarla y conservarla tal y como el paso del tiempo la había hecho llegar hasta el presente, liderada desde Inglaterra por Ruskin. Esta nueva forma de entender el patrimonio -particularmente el patrimonio arquitectónico- lleva a la creación de instituciones encargadas de estudiar sus orígenes y su evolución, y surgen así la Société Française d'Archéologie, en 1834, la British Archaeological Association, de 1843, o la Real Associaçao dos Arquitectos Civis e Archeologos Portugueses, en 1863 (Mederos, 2010: 178).

En España, esta corriente se plasmó en la colección Monumentos arquitectónicos de España, que entre 1859 y 1881 publicaría los volúmenes de Alicante, Ávila, Badajoz, Barcelona, Burgos, Cáceres, Córdoba, Gerona, Granada, Guadalajara, León, Madrid, Mérida, Oviedo, Salamanca, Segovia, Toledo, Valencia, Valladolid y Zamora; aunque también en iniciativas más locales o regionales, como la de Víctor Balaguer, en 1853 , cuando pide salvar las "cuatro perlas que lucen en el collar de Catalunya", refiriéndose a los monasterios de Poblet, Santes Creus, Ripoll y Sant Cugat (Ballart y Juan, 2008: 47).

\section{La creación de la Escuela Superior de Diplomática}

Es en este entorno - con el consabido retraso temporal que imperaba en España- cuando se crea en la Escuela Superior de Diplomática de Madrid la que sería la asignatura que recogía esos avances en la arqueología de los grandes monumentos (Escuela Superior de Diplomática, 1865, 22) 2 , y que aquí se denominó "Historia de las Bellas Artes en los tiempos antiguos, Edad Media

2 Aurora Godín Gómez (Godín, 1995) lo cita como escrito por Pedro Felipe Monlau y Roca; no aparece sin embargo firma alguna en el documento, por lo que lo cito como Reglamento de la ESD. y Renacimiento"; la asignatura de Juan Facundo Riaño (Maier, 2008b: 184).

La Escuela expedía también, como se ha explicado, el título de Archivero, Bibliotecario y Conservador de los Museos de España, al haber sido incorporados al Escalafón del Cuerpo de Archiveros y Bibliotecarios todos los Catedráticos de la Escuela de Diplomática, el 10 de abril de 1867, acaparando así la formación no sólo de los encargados de desenterrar - de la tierra o de los archivos- el patrimonio cultural de España, sino también de los que debían catalogarlo, exponerlo y conservarlo (Escuela Superior de Diplomática, 1865: 1); la labor de esta institución fue, por tanto, fundamental en la metodología seguida desde que se encontraba el bien hasta que se exponía en un museo, e influyó decisivamente en la forma de entender y proceder en aquellas profesiones en las que se trabajaba con antigüedades, tanto escritas como objetos, arqueológicos o no.

Hasta ahora, sobre el proceso por el cual Juan Facundo Riaño obtuvo su plaza de Catedrático, tan sólo se tenían datos sobre cómo - una vez conseguida la plaza de profesor interino- se le adjudicó la plaza de catedrático en propiedad; nada se sabía, sin embargo, del proceso por el que llegó en primer lugar a la Cátedra interina de Historia de las Bellas Artes en la Escuela Superior de Diplomática de Madrid, suponiéndose, lógicamente, que el nombramiento estaba relacionado con un turbio proceso por el cual se le escatimó la plaza de profesor de Teoría e Historia de las Bellas Artes en la Escuela Superior de Pintura, Escultura y Grabado de Madrid (López-Ocón, 2010), que le correspondía legalmente al haberse clasificado primero de una terna, en unas oposiciones que se realizaron en 1861. Gracias al descubrimiento de gran parte del epistolario inédito de Riaño, se puede ahora iluminar el proceso por el cual llegó a ocupar dicha plaza, que fue la verdadera asignatura de arqueología en la Escuela (Maier, 2008b: 186). Riaño ocupó su plaza desde su nombramiento, en julio de 1863, hasta su jubilación como catedrático, en 1888; fue por tanto profesor de la verdadera asignatura de arqueología durante 20 años -pues fue cesado durante el sexenio revolucionario- contando entre sus alumnos en dicha Escuela a José Ramón Mélida o a Juan Catalina García, que a su vez llegaría a ser profesor de la Escuela Superior de Diplomática.

Sobre la historia de la Escuela Superior de Diplomática y su importancia en la arqueología española se ha escrito abundantemente (Escuela Superior de Diplomática, 1865; Godín, 1995; Pasamar y Peiró, 1996; Berlanga, 2001; Romero, 2005; García 2007; Maier, 2008b), por lo que no profundizaré aquí sobre ella, ya que no es el objeto de este artículo. También se ha escrito superficialmente sobre Juan Facundo Riaño, sin embargo, es mucho lo que falta por investigar aún sobre la verdadera importancia de su figura, tanto en el ámbito académico como en el pedagógico; este artículo forma parte de una investigación exhaustiva que trata de averiguar el verdadero peso que tuvo en la vida cultural y política de la segunda mitad 
del s.XIX, y en la creación de instituciones pedagógicas fundamentales en la historia reciente de España.

\section{Juan Facundo Riaño y la Cátedra de Teoría e Historia de las Bellas Artes en la Escuela Superior de Pintura, Escultura y Grabado}

Juan Facundo Riaño pertenecía a una familia acomodada de Granada, con numerosas posesiones y negocios en la provincia. Siendo muy joven -a la edad de 7 años-murió su padre, quedando su madre al cuidado de los tres hermanos, del que él era el primogénito; no teniendo problemas económicos, Riaño se crió en Granada hasta probablemente 1845, en que arregló sus obligaciones con el servicio de quintas y tomó su primera diligencia con destino a Madrid. Existen actualmente varias versiones e interpretaciones sobre cuándo hizo Riaño un viaje por varios países de Europa, siendo la que cuenta con más predicamento la que fecha su inicio en 1851; no es este el momento para un examen extenso, pero si puedo asegurar que Juan Facundo Riaño tenía su residencia habitual en Granada en 1851, ya que se matriculó en 1849 en los estudios de segunda enseñanza, y asistió entre 1850 y 1854, como oyente, a los estudios de árabe que impartía José Moreno Nieto en la Universidad Literaria de Granada, como consta en su expediente (Exp.1, 1863) y recogió Salvador Torres en su "Elogio de Don José Moreno Nieto" (Torres, 1882: 479), tesis que refuerza una carta fechada a 16 de junio de 1852, dirigida por el arabista francés Reinhart Dozy a Riaño. Aun así, probablemente Riaño realizó diferentes viajes entre 1851 y 1854 , entre ellos a Londres en 1851, y a Italia entre 1853 y 1854 . De regreso a Granada, ingresó en la Academia de Bellas Artes de esa ciudad y se matriculó -como se ha visto- en los estudios oficiales de segunda enseñanza en 1849, con 21 años (debería haber empezado sus estudios de $2^{\mathrm{a}}$ enseñanza en 1838), recibiendo el grado de Bachiller en 1855, y el Bachillerato en Filosofía y Letras en septiembre de 1860; con este título solicita ser admitido, en noviembre de 1860 , en la oposición a la Cátedra de Teoría e Historia de las Bellas Artes en la Escuela Superior de Pintura, Escultura y Grabado de Madrid, que tendría lugar en Madrid entre enero y febrero de 1861. El resultado de esos exámenes fue que Juan Facundo Riaño quedó primero, Juan José Martínez de Espinosa segundo y Manuel de Assas tercero; especificando el tribunal que El primero se ha distinguido en los ejercicios por sus conocimientos arqueológicos y filológicos. A pesar de su publicación, el puesto recayó finalmente en el segundo clasificado, Martínez de Espinosa, sin que se supiera a ciencia cierta el porqué; habría quizá que buscar la respuesta en que el Teniente General de la Armada, Juan José Martínez de Espinosa y Tacón, era de absoluta confianza de O'Donnell, quien lo nombraría Consejero de Estado el 6 de noviembre de 1861 .

A partir de esa fecha, y hasta el 16 de julio de 1863, se abre una laguna que hasta ahora se había rellenado con la suposición de que el nombramiento era una compensación atrasada a la injusticia de la oposición de 1861, y que pro- bablemente se había conseguido gracias a su suegro -por entonces aún futuro- Pascual de Gayangos y Arce, que era quien tenía los contactos en las altas esferas políticas por esa época.

El 22 de febrero de 1861, el mismo día en que Riaño hacía el último examen de oposición, publicaba el periódico La Correspondencia de España que Riaño acaba de ser propuesto en primer lugar por el tribunal de oposiciones para la cátedra de Teoría é Historia de las Bellas Artes; en la Academia de San Fernando, en el mismo párrafo daba noticia de su nombramiento como miembro del Instituto Arqueológico Imperial Alemán de Berlín y Roma, publicándose además que también los hermanos Oliver eran distinguidos con ese nombramiento. Sobre los Oliver se dice que han sido nombrados en atención al brillante trabajo sobre la antigua ciudad de Munda (Oliver y Oliver, 1861), de Riaño, sin embargo, no se especifican los méritos; se puede suponer, con cierta seguridad, que el nombramiento se debía a que entabló relación con Emil Hübner, que estuvo en España entre marzo de 1860 y octubre de 1861 (Mederos, 2010: 195), y con quien mantendría contacto y correspondencia - personal y profesional- a lo largo de los años, entre otros asuntos sobre los descubrimientos del Cerro de los Santos, más tarde conocidos como de Yecla. Parece lógico suponer que los conocimientos arqueológicos y filológicos que alabó el tribunal en su resolución, convenciesen también a Hübner de la conveniencia de nombrarle miembro de la Institución que representaba, a pesar de no tener muchos estudios oficiales aún.

Entre el epistolario de Riaño -inédito aún- existen varias cartas que ayudan a entender cómo se desarrolló el proceso de la oposición, y seguramente como se desarrollaban habitualmente estos asuntos en la España del s.XIX, donde el nepotismo, el amiguismo y los favores entre políticos eran moneda corriente.

En carta fechada a 1 de abril de $1861^{3}$, todavía aturdidos en el círculo de Riaño por la inesperada sucesión de los hechos, se da cuenta de los intentos de enterarse de quién es el responsable del nombramiento de Martínez de Espinosa en lugar de Riaño: Esta mañana he recibido una carta de Gayangos avisandome su vuelta, y q me esperaba en su casa de 11 a 1: he ido y me ha dicho q en Aranjuez ha hablado con El Marques de $S^{n}$ Gregorio, y con Antonio Flores. El primero no quería creer el atropello del Ministro, y quedó en hablarle de una manera enérgica, diciendo q era un escándalo q tal sucediese. El otro ha hablado a la Reina del asunto, y S.M. le ha manifestado $q$ era completamente falso el q ella hubiese empeño por el $2^{\circ}$ lugar, pues era la primera noticia $q$ de tal negocio tenia. Esto hay, sin q se sepa aun si estos ultimos pasos han producido resultado [...] El suelto q te remito de un

Madrid, 1 de abril de 1861. Firmada con el pseudónimo de Raya (a quien identifico como Mariano Vázquez Gómez), dirigida a Aguilar, posiblemente Antonio Almendros Aguilar; ambos miembros de $\mathrm{La}$ Cuerda Granadina y amigos de Riaño. 
periodico ministerial (pues la Verdad lo es) es algo significativo de la perplejidad en q se encuentra el Ministro. Las demas noticias ya las sabes por los demas y yo aqui me quedo y paso a otras cosas. A Aureliano no le he visto. Nada produjeron esos últimos pasos, a pesar de que el Marqués de San Gregorio era el médico personal de la Reina, y Antonio Flores Jefe de Sección de la Intendencia General de la Casa Real. De esta carta se puede extraer, entre otras cosas, que efectivamente Pascual de Gayangos tenía los contactos en las altas esferas, y que ya consideraba a Riaño de suficiente confianza en su familia como para molestarse por él. Sea como fuere, los contactos de Gayangos no sirvieron de gran cosa, ni lo harían en el futuro, como se verá. El Aureliano que nombra es Aureliano Fernández-Guerra, quien aparecerá abundantemente en posteriores cartas, por entonces en la Secretaría de Instrucción Pública, del Ministerio de Fomento, con quien Riaño y su grupo tenían amistad -unos más que otros-y en común el haber estudiado en Granada.

La segunda carta está fechada a 11 de agosto de $1861^{4}$, si bien existen más cartas intermedias, aunque sirven sólo para constatar el estado de ánimo de Riaño, que dice de si mismo que emplea el tiempo en murmurar y lamentarme de cierto señor que le dicen el sonámbulo; el que escribe la carta lo hace como representante de Riaño -quien se había refugiado en su Granada natal, totalmente desconsolado con el giro inesperado de los acontecimientospara rechazar un soborno que le hacen llegar a través de su amigo Lafuente Alcántara, quien sin duda, como todas sus amistades, intentaba por sus propios medios remediar la situación. En ella, tras los prolegómenos de rigor, se dice: Riaño no quiere destino alguno ni del gobierno ni de los particulares. Posee una buena fortuna [...] que ha ganado, y que hoy le facilita la posibilidad de no vender el primer puesto de una terna. Si el fuera capaz de una transacción semejante sería indigno de la cátedra. Queda $V$. por consiguiente autorizado a dar las gracias al amigo que, llevado sin duda del mejor deseo, le indica la benevolencia del Ministerio para con Riaño, y asegurar que este no necesita ni quiere nada. Sorprende ligeramente que desde el ministerio (supuestamente de Fomento) se le ofrezca una plaza habiendo ya obtenido una, aunque en siguientes cartas se aclara en gran medida. Sea como fuere, parece que Riaño rechazó un nombramiento no conseguido por él, centrándose en sus estudios de Derecho y Filosofía y Letras; termina la carta preguntando por el nombramiento de Martínez de Espinosa, encargándole que le avisase en cuanto se expidiesen las órdenes para escribirselo al $S^{r}$ Moreno Lopez y al $S^{r}$ Gayangos, quienes se fueron de Madrid confiados en la espontánea y solemne palabra del Marques de Corvera. Sobre

Madrid, 11 de agosto de 1861. Firmada con las iniciales CyS (a quien identifico como José de Castro y Serrano, de La Cuerda Granadina), dirigida a Emilio Lafuente Alcántara, amigo y compañero de Riaño en las clases de árabe de José Moreno Nieto en la Universidad Literaria de Granada.
Moreno López hablaré más adelante, pues aún habrá de jugar un papel importante en este asunto. No puede ser fortuita esta referencia al Marqués de Corvera, por entonces Rafael de Bustos y Castilla-Portugal, VIII marqués de Corvera, quien era en ese momento el Ministro de Fomento y Diputado a Cortes por Murcia, ni la mención de la palabra espontánea; parece desprenderse de la carta que el Ministro se mostró convencido de la superioridad de Riaño y no recordó ningún impedimento a su nombramiento, y que los siempre presentes favores de la política española debieron ser demasiado poderosos para molestarse por alguien a quien nada debía, bien sea Riaño o Gayangos. Quizás el mismo Ministro tuvo que faltar a su palabra contra su voluntad, si hay que dar por buena la teoría esbozada en la primera carta, a propósito de la perplejidad de Corvera. Sin embargo, desde el ministerio, alguien consciente de la evidente injusticia de los hechos, se ofreció a su vez a nombrarle a dedo para otro puesto. No debía contar con la negativa de Riaño, una muestra de honradez seguramente poco habitual en aquella época. La duda que surge es ¿quién es el responsable de que Riaño no ocupase su plaza, quien es el sonámbulo?, y ¿Quién le ofrece la plaza en compensación?; la siguiente carta despeja parcialmente esa duda.

La tercera carta, dirigida a Riaño, es de 7 de octubre de $1861^{5}$, para entonces los ánimos estaban ya mucho más calmados, los hechos se daban por consumados y perdida la causa, por lo que casi toda la carta trata sobre otros temas, como el anuncio por parte de Cruzada Villaamil de que la revista La Razón dejaba de existir, pero veía la luz La Revista Ibérica; tan sólo al final de la carta, hablando Fernández Jiménez sobre un amigo común (sin relación con el caso) dice dirigiendo Corvera la instrucción pública es fácil aspirar á una barberia ó ventorrillo cuando menos, con tal q no se haga ni oportuna ni legalmente. Parece claro que el sonámbulo es Corvera, que debió considerar que otros favores debidos eran más importantes que la palabra dada -algo muy posible en el caso de que fuera el mismo O'Donnell el que interviniese- o simplemente se le llamase así por la perplejidad en la que cayó ante un nombramiento para el que O'Donnell ni siquiera se molestó en consultarle, algo no del todo descartable; aunque teniendo en cuenta que murió un mes después de la fecha de la carta, era seguramente también un mote muy realista sobre su condición física. Pero falta por saber quien ofreció la plaza a Riaño. Podría ser el mismo Corvera, cuyos remordimientos por la palabra dada y no cumplida le incitasen a ello, pero la carta de octubre no parece respaldar esta hipótesis; a juzgar por la trayectoria de los empleados en el ministerio, la única persona que parece capaz de ofrecer una plaza para subsanar una

5 Madrid, 7 de octubre de 1861. Firmada por Gregorio Cruzada Villaamil (protector de la Colonia Granadina, La Cuerda Granadina en Madrid) e Ivón, apodo de José Fernández Jiménez en La Cuerda Granadina; dirigida a Juan Facundo Riaño, en Granada. 
injusticia sin recibir algo a cambio parece ser Aureliano Fernández-Guerra, por entonces Secretario de Instrucción Pública y hombre con fama de honrado, las razones para elegir ese nombre no son fortuitas.

\section{Aureliano Fernández-Guerra}

Aureliano había estudiado en Granada, donde conoció a Riaño, y era amigo de los hermanos Oliver Hurtado -siendo además secretario del tribunal de la Real Academia de la Historia que en 1861 premió la obra Munda Pompeiana (Oliver y Oliver, 1861: V)-y le unía también una estrecha amistad a toda la familia Lafuente Alcántara; particularmente a Emilio, a quien recomendó en diversas ocasiones y finalmente nombró miembro del Cuerpo de Archiveros y Bibliotecarios, en 1863 (Miranda, 2005: 132). La carta 2 (de agosto de 1861) está dirigida precisamente a Emilio Lafuente Alcántara -que en otras cartas se le menciona como asiduo de la casa de Riaño en Madrid-y se le pide que de las gracias «al amigo que, llevado sin duda del mejor deseo, le indica la benevolencia del Ministerio para con Riaño»; además, Aureliano contestó -el 28 de diciembre de 1862- en nombre de la Real Academia de la Historia, en la Recepción Pública de Eduardo Saavedra, amigo de Juan Facundo Riaño y el encargado de contestarle, en nombre de la misma Academia, en su Recepción Pública como Individuo de número. Para terminar, durante el episodio del caballo -del que se hablará más adelante- uno de los que acompañaron a Aureliano en su convalecencia fue José Oliver y Hurtado, con el que Riaño tenía una gran amistad y quien era habitual de su casa; incluso se ha llegado a incluir el nombre de Fernández-Guerra como miembro de La Cuerda Granadina (Gallego, 1991: 15), la tertulia a la que pertenecía Riaño en Granada, punto que me parece exagerado, dada la extensión del listado que recoge, si bien indica que se conocían, trataban y tenían comunes amistades. No existe una prueba definitiva, por el momento, pero no es descabellado pensar que ese amigo pudiera ser Aureliano Fernández-Guerra, dados los muchos vínculos que les relacionan y el hecho de que su nombre aparezca en la carta de abril.

En el año 1862 hay un vacío casi absoluto de cartas -probablemente porque Riaño se estableció de nuevo en Granada-, aunque no de información. La mayor parte del tiempo la empleó intentando solucionar la convalidación de sus estudios de árabe en la Universidad de Granada, para poder obtener el título de Licenciado en Filosofía y Letras; aunque también sacó tiempo para viajar en verano con Pascual de Gayangos y su hija Emilia a París, donde parece que se dedicó a estudiar en profundidad el Louvre, y para formar parte de la comitiva que agasajó a la Reina en su visita a Granada, a finales de año. Probablemente fruto de esa visita, y de las amistades de Riaño, fue la concesión a Juan Facundo Riaño de la medalla de Carlos III y el título de caballero de Isabel la Católica. Por posteriores cartas, se deduce que durante 1862 siguió intentando que se le hiciera justicia en el asunto de la oposición y designase para un puesto de profesor similar, al parecer infructuosamente.

Ya en enero de 1863 vuelven las cartas, pero no será hasta el 14 de abril de $1863^{6}$ cuando empiecen las referencias al personaje que será clave en el nombramiento de Riaño como Catedrático de la Escuela Superior de Diplomática, el Senador José María Huet y Allier. En abril de 1863 Riaño había adquirido dos costumbres, parece que sin relación entre ellas; visitar a la familia Huet en su casa y al funcionario del ministerio - de Fomento, se entiende- al que llamaba Cailla. En esta carta a Cailla no se le nombra sino indirectamente Ahora me voy un rato al ministerio á calentarle la oreja á aquel amigo. Él, mientras tanto, procurará vengarse, como hace otros dias, dandome algun apunte $p^{a}$ que se lo saque a limpio ó cosa parecida. Yo digo como los jugadores de cartas: mientras se baraja no se pierde. Las referencias a Huet son mucho más cálidas, dando muestras de su trato continuado y familiar Anoche estuve en casa de Huet q como siempre estuvieron conmigo lo mas atentos del mundo. No he conocido nunca una familia q merezca tanto $q$ se la quiera y se la respete. La señora, como de costumbre, me llenó un bolsillo de pastillas y de caramelos, y los dos me dieron expresiones $p^{a}$ la señora ${ }^{7}$; lo que me lleva a descartar que hubiese un motivo interesado en esta relación, especialmente por la referencia a la madre de Riaño, que indica una relación de familias. La relación entre la familia Huet y Riaño debió ser muy cercana, y no debe ser casualidad que el propio Juan Facundo Riaño ocupase la medalla que ostentaba Huet en la Real Academia de la Historia, a la muerte de este, y le reconociese como ademas de maestro, como un padre cariñoso, y el más tolerante y más afectuoso de los amigos (Riaño, $1869,6)$. La relación de Gayangos con Huet, por el contrario, me es desconocida, es de suponer que se conocían y trataban, siendo la sociedad madrileña tan endogámica, pero en las referencias que hace Riaño de visita a la casa de Huet nunca menciona a este; sin embargo, varias veces recoge haber ido a casa de Gayangos -al que aún llamaba Don Pascual y donde, al fin y al cabo, vivía su futura mujer- tras la visita a casa de Huet, como hechos no relacionados. Tampoco conviene pasar por alto que, desde el 3 de marzo de 1863, había sido nombrado un nuevo Ministro de Fomento, Manuel Moreno López -al que se debía escribir en la segunda carta- quien nombró a su vez Secretario General de Instrucción Pública a Aureliano Fernández-Guerra.

A 20 de abril de $1863^{8}$ dice Riaño Lo que me dices de la moneda de Iliturgi no lo echaré en saco roto, y creo $q$ podrá servirme $p^{a}$ suavizar un poco al amigo Cailla [...]

6 Madrid, 14 de abril de 1863. Firmada por Juan Facundo Riaño, dirigida a su hermano Bonifacio Riaño, en Granada.

La señora, o Señora, es una forma habitual de JFR de referirse a su madre, $\mathrm{M}^{\mathrm{a}}$ Dolores Montero.

8 Madrid, 20 de abril de 1863. Firmada por Juan Facundo Riaño, dirigida a su hermano Bonifacio Riaño, en Granada. 
Por ahora no te digo q me la mandes, y ya cuidaré yo de avisartelo cuando me haga falta; Iliturgi es una antigua ciudad íbera-Iliturgi Forum Iulium-, en el actual término municipal de Mengíbar (Jaén), fue conquistada y destruida por Roma. No aparece en ninguna otra carta referencia alguna a la moneda de Iliturgi, pero lo cierto es que según pasan los días la relación entre ambos se va suavizando; así en la siguiente carta, de tan sólo 2 días después -22 de abril de $1863^{\circ}$ - ya se refiere a él de manera más cordial diciendo Ayer estuve á ver al simpático Cailla que ahora está muy fino conmigo; solamente que á vueltas de su finura me pega cada tártago de escribir y de ayudarle en sacar cosas en limpio que tiembla el eje. Pero en fin, yo prefiero esta á aquella frialdad de antes que no permitía jamás ni aun el tratar lo mas pequeño de mi asunto. A partir de aquí ya se empiezan a ver los progresos de Riaño en su intento de obtener una plaza, que ya debía tener pensada y -probablemente- hablada con Pascual de Gayangos, quien seguramente le asesoraba en los pasos que debía dar para conseguirlo. En la misma carta reaparece Huet, No pude oir á este mas q las tres primeras porque eran las 6 de la tarde y tenía $q$ ir a ver al $S^{r}$ Huet y después ir á las 7 á comer á casa de Gayangos; claramente en la vida de Riaño, las familias Gayangos y Huet no estaban relacionadas.

A partir de la carta del 6 de mayo de $1863^{10}$ se produce un cambio curioso, cesa toda referencia al funcionario Cailla y aparece en escena Don Aureliano, a quien hasta ahora no se había nombrado: Antes sucedia q después de levantarme me estaba leyendo y escribiendo hasta las dos ó las tres y entonces me solia ir un rato al ministerio y á hacer unas cuantas visitas. Ahora voy al ministerio después de almorzar porque es la mejor hora $p^{a} D^{n}$ Aureliano y porque suele encargarme q le ponga en limpio algunas cosas, y ocurre con esto q pierdo toda la tarde. De repente, desaparece el misterioso amigo Cailla, el que se vengaba dándole algún apunte para pasar a limpio y le pegaba tártagos de escribir, y es Aureliano Fernández-Guerra el que le encarga que pase a limpio documentos; ¿son Aureliano y Cailla la misma persona? La explicación podría remontarse al 26 de marzo de 1860, cuando Aureliano, viajando entre Torredonjimeno y Baena (Córdoba), se cayó del caballo, rompiéndose ambos brazos y teniendo que pasar dos meses de convalecencia en la casa de su madre; el asunto fue muy comentado en la época, llegando incluso a la prensa (Miranda, 2005: 118-120).

El negro sentido del humor que implica esta broma, entre Cailla y calló (cayó), cuadra perfectamente con el que solía usarse en las tertulias de La Cuerda Granadina, pues tanto Juan Facundo como su hermano Bonifacio eran miembros, y del que se conservan abundantes ejemplos en sus cuadernos de sesiones; como el mote dado a Francisco

9 Madrid, 22 de abril de 1863. Firmada por Juan Facundo Riaño, dirigida a su hermano Bonifacio Riaño, en Granada.

10 Madrid, 6 de mayo de 1863. Firmada por Juan Facundo Riaño, dirigida a su hermano Bonifacio Riaño, en Granada.
Rodríguez Murciano (Tenazas), por haber utilizado unas tenazas de chimenea para matar -o herir de gravedad, pues es un detalle que se evitaba especificar-a un súbdito inglés en una discusión, cuando residía en Londres, a resultas de lo cual hubo de huir del país y refugiarse de nuevo en Granada. El asunto fue muy celebrado en el grupo e inspiró no pocas chanzas, como toda una serie de dibujos coloreados en la que relataron las peripecias de su viaje a Londres, tenazas incluidas, y que se conservan en el museo La Casa de Tiros de Granada.

Sea como fuere, parece establecerse una relación bastante plausible entre Cailla y Aureliano por la coincidencia entre las tareas de copiado, el hecho de pasar toda la tarde, y el no haber podido localizar hasta el momento a ningún funcionario de apellido Cailla; pues, si bien es cierto que Fernández-Guerra tenía dos ayudantes, estos parecen ser José Godoy y Manuel Cañete, que ingresaron en la Secretaría de Fomento en julio de 1862 y marzo de 1863 respectivamente (Miranda, 2005: 222). Por lo que respecta a Huet, sigue apareciendo en sus cartas y afirmándose la estrecha relación que los unía, es esta ocasión recoge Riaño La hermana del $S^{r}$ Huet se murió el dia 4 por la madrugada. Ayer asistí al entierro en San Sebastián y después fui acompañando el cadáver hasta el cementerio [...] Por la noche estuve en casa de D ${ }^{n}$ José Huet y estuvo conmigo tan complaciente como siempre.

Dos días después, en la carta del 8 de mayo de $1863^{11}$, la operación de ablandamiento de Aureliano Fernández-Guerra prosigue He tenido q dar a $D^{n}$ Aureliano los dos calcos de la piedra del Albaicin, de manera q será menester q hagas otro par de ellos $p^{a}$ q los guardemos nosotros; pues mañana ó el otro se nos puede ocurrir tener q servir á algún amigo, y cumple uno regalando una cosa q vale tan poco. Ahora lo veo todos los dias. Así que almuerzo me sofilo en su oficina, y, quieras que no, no tiene más remedio que entrar en conversación conmigo, que es una de las cosas á que siempre le ha huido el bulto. Parece afirmarse que aquel Cailla, cuya frialdad de antes no permitía tratar lo más pequeño del asunto, es el mismo que este Aureliano, que siempre le ha huido el bulto; esto podría casar con la carta del 11 de agosto de 1861, porque si realmente fue Fernández-Guerra el que le ofreció el puesto, podría haberse ofendido por la respuesta de Riaño a su desinteresado ofrecimiento, negándose a sacar de nuevo el tema aunque sin dejar de tratarle, ya que se conocían y tenían amigos comunes. La relación con Huet -que a la postre resultará fundamental en la resolución del proceso- sigue tan cordial como siempre; Por la noche voy un rato a casa del Sr. Huet. La Señora, q. tiene un carácter envidiable, dice q no se anima José María hasta q. yo voy, y q. por consiguiente q. vaya siempre q pueda [...] es un trato tan amable el de esta familia y tiene tantas atenciones conmigo, que no me canso de dar gracias a Dios $p^{r}$ haberme proporcionado el

11 Madrid, 8 de mayo de 1863. Firmada por Juan Facundo Riaño, dirigida a su hermano Bonifacio Riaño, en Granada. 
gusto de conocerlos. Siempre me preguntan $p^{r}$ la Señora y me encargan expresiones.

Entre el 8 de mayo y la siguiente carta, fechada a 11 de junio de $1863^{12}$, no hay cartas en las que se hable del proceso, ya que era con Bonifacio Riaño -el hermano-con quien se desahogaba de sus inquietudes y a quien mantenía al tanto de los progresos con la Administración, dejando las cartas a su madre para asuntos más alegres; Bonifacio pasó aproximadamente un mes en la casa madrileña de Juan Facundo, donde tratarían de la oposición más allá de los estrechos límites del papel.

En esta novena carta (novena para este propósito), se habla por fin abiertamente del puesto que persigue Riaño, $\mathrm{y}$ de los procesos que le retienen en Madrid e impiden que se vaya de vacaciones estivales a la casa familiar en Granada; Yo continuo en el mismo estado sin saber con seguridad el dia de mi marcha. Todos los dias voy al ministerio á ver si mandan el decreto del arreglo de la Escuela á q. lo firmen en la Granja, pues hasta tanto q. no vuelva no podran darme el nombramiento. Algo por fin se movía, aunque es difícil averiguar cómo y porqué, pero parece claro que su relación con Aureliano Fernández-Guerra, por el que al fin y al cabo pasaban todos los decretos del ministerio, había engrasado la maquinaria burocrática y su candidatura era firme para un puesto en la Escuela Superior de Diplomática; las influencias para remodelar la Escuela en ese momento, habrá que buscarlas seguramente en unas más altas esfera que las de Fernández-Guerra. En este punto es recomendable recordar quién era el Ministro de Fomento en ese momento, Manuel Moreno López, ya nombrado en la carta de agosto de 1861 .

En cuestión de un mes, los acontecimientos se aceleran inesperadamente y Riaño verá por fin cumplido su anhelo de ocupar una plaza de profesor; el día 9 de julio de $1863^{13}$, Juan Facundo escribe, nervioso, Mi viaje á Granada no lo veo ahora tan inmediato como quisiera, pues en el estado en q. se encuentra el expediente de la Escuela no es prudente abandonarlo, según me dicen Aur ${ }^{\circ}$ y todos. Tengo que esperar á q. se firme el decreto de la organización de la Escuela y como consecuencia de este arreglo deben darme mi nombramiento interino. Como la Reina está en la Granja y los ministros andan cada cual $p^{r}$ su lado, sucede q. el despacho se entorpece á cada momento y no hay mas remedio que esperar. Riaño, en este momento, sabe ya qué puesto tendrá y con que categoría, algo en lo que probablemente Gayangos tuvo bastante responsabilidad, habiendo sido en su momento uno de los responsables de la creación de la Escuela Superior de Diplomática, casi diez años antes, y siendo el padre de su futura mujer, a la que Riaño debería mantener con su trabajo, según era costumbre en esa época.

12 Madrid, 11 de junio de 1863. Firmada por Juan Facundo Riaño, dirigida a su hermano Bonifacio Riaño, en Granada.

13 Madrid, 9 de julio de 1863. Firmada por Juan Facundo Riaño, dirigida a su hermano Bonifacio Riaño, en Granada.

\section{Catedrático interino de Historia de las Bellas Artes}

En carta de 13 de julio de $1863^{14}$, Riaño da cuenta de una feliz coincidencia que precipitará todos los acontecimientos. Pascual de Gayangos se marchaba (como cada verano) a Londres, acompañado de su hija Emilia; en esta ocasión, al igual que sucedió el verano anterior, invitó a Juan Facundo a que les acompañase al menos hasta Ávila, ya que tenía que quedarse en Madrid, pendiente de su nombramiento. Debido a la reciente inauguración -en 1863- del tramo Ávila-El Escorial (que formaba parte de la ruta Madrid-Hendaya, y que conducía a Londres vía París), Riaño accedió a pasar un par de días alejado de la Corte, afortunadamente para él. Nada hay reseñable en la carta, pero explica qué hacía Riaño en Ávila, y los acontecimientos posteriores; y da una idea de lo rápido que se sucedieron todos los trámites en pocos días.

La carta del 17 de julio de $1863^{15}$ (viernes) es ya la crónica de un decreto firmado, y una excelente muestra de cómo se cerraban los acuerdos, los nombramientos y cualquier otra cosa en la España de mediados del s.XIX. Se trata de una extensa carta de 11 caras -cuando lo habitual eran 3 ó 4 en la que un optimista Riaño da detallada cuenta de cómo se habían sucedido los acontecimientos, aunque naturalmente reproduzco tan sólo lo relacionado con este estudio.

Yo me fui el lunes, según te avisaba, con $D^{n}$ Pascual y Emilia $p^{a}$ pasar un par de dias en Avila. Alli hemos estado hasta el miércoles pr la mañana en que ellos siguieron su viaje hacia Valladolid y yo me volví á la Corte [...] Estando ese mismo dia en la estación de Avila esperando a q. saliera el tren donde iba $D^{n}$ Pascual, me encontré á $D^{n}$ Aureliano asomando la cabeza por la ventana de un coche. Era que se marchaba a Vitoria á pasar un mes de verano. Enseguida q lo vi me dirigí á el y le pregunté $p^{r}$ mi asunto: me contestó $q$ no habia venido el decreto y $q$ no dejara de ir todos los dias á ver á su auxiliar que era el que quedaba al cargo de su negociado y que quedaba tambien al cuidado de mi asunto. Este sistema de recetar no lo pierde $D^{n}$ Aurel $^{o}$ aunque lo quemen. El $S^{r}$ Huet me escuchó atentamente, y me prometió que desde aquel momento habia de interesarse a favor mio, y q. si no conseguia nada no habia de quedar porque el no hiciese todo lo q. estuviera de su parte. A la mañana siguiente fué á ver á Aureliano y lo encontró decidido completamente a favor mio. Hablaron con extensión del asunto y se convinieron en los pasos q. era necesario q. diese $D^{n}$ José $p^{a}$ no dar un golpe en vago; pues en el mismo dia tantearon el animo del Director y no lo hallaron muy propicio á hacer ninguna gracia. Habia ocurrido entre tanto la crisis del Gobierno, quedando definitivamente nombrado $p^{a}$ Fomento el $S^{r}$ Moreno Lopez, y dio la afortunada coincidencia de

14 Madrid, 13 de julio de 1863. Firmada por Juan Facundo Riaño, dirigida a su hermano Bonifacio Riaño, en Granada.

15 Madrid, 17 de julio de 1863. Firmada por Juan Facundo Riaño, dirigida a su hermano Bonifacio Riaño, en Granada. 
$q$ Huet era muy amigo suyo. Huet dudaba de q el ministro le hiciese todo el caso q era menester $p^{a}$ dar una resolucion definitiva, y queria esperar á q se abriese el Senado $p^{a}$ ofrecerle su voto y ligarlo mas de esta manera; pero Huet tiene el genio muy vivo, y no pudiendo contenerse demasiado tiempo fué una mañana á hablarle. El ministro debió recibirlo con tanta atencion y él, ademas, debió interesarlo tanto, que á la mañana siguiente habia preguntado tres ó cuatro veces $p^{r}$ el expediente, y el Director llamó a Aureliano y le dijo q era menester arreglar á todo galope la reforma de la Escuela de Diplomática. En suma, á los tres o cuatro dias el Negociado habia puesto su informe, el Director habia firmado la conformidad y el Ministro habia decretado al margen del expediente el pase al Consejo de Instrucción Pública [...] El asunto, $p^{r}$ consiguiente, pasó al Consejo después de haber estado durmiendo en el despacho del director $p^{r}$ espacio de 12 meses. Es imposible, completamente imposible describir la eficacia y el calor con que el $S^{r}$ Huet ha trabajado desde el principio. [...] Cuando llegó el expediente al consejo la emprendió con los consejeros, uno $p^{r}$ uno, y tanto les debe haber apretado que en la segunda sesión que han celebrado acaban de aprobar en todas sus partes el expediente, con el informe del ministerio que puso Aureliano á nuestro gusto. La aprobación del Consejo ha sido ayer y como esta es verdaderamente una buena noticia no he querido retardar más tiempo el q. la sepas. [...] Hay que hacer ahora un real decreto, frmadopor la Reyna, en donde se haga oficialmente la reforma de la Escuela tomando por base la resolucion del Consejo. Una vez firmado el decreto por la Reyna, el ministro proveerá la plaza que se crea haciendo $q^{e}$. recaiga en persona competente, cuya persona es menester que sea yo. Tu comprenderás ahora la exposicion en $q^{e}$. estoy de $q$ venga algun paniaguado del Gobierno, y, ya $q^{e}$. tengo tan bien preparado el campo, interponga influencia y derribe mis ilusiones. Dios quiera que no porque entonces era cosa de desesperarse. Otros males hay también q temer pero yo cuento con dominarlos, pues Aureliano está completamente de mi parte y no puedes pensar lo q nos ha servido. Creo yo q. sin él hubiera sido imposible este arreglo. [...] En fin, lo principal de todo es q el ministro de Fomento no caiga de su sitio; porque si cae el ministro me pierden.

Hasta aquí un extracto de la carta del 17 de julio, como se puede ver, la amistad de Juan Facundo Riaño y José María Huet -y la de éste con Manuel Moreno López- fue la que precipitó los acontecimientos. También reconoce Riaño la continuidad de Moreno López como condición suspensiva, y la importante labor de Aureliano Fernández-Guerra en el proceso, lo que explicaría el porqué de la afirmación de Rada y Delgado en sesión ordinaria de la Real Academia de San Fernando, el lunes 4 de marzo de 1901, cuando - con motivo de la reciente muerte de Riañodecía, a propósito de la injusticia de 1861, que siendo propuesto en primer lugar para la Cátedra de la Escuela de Diplomática le fue concedida al que ocupaba el segundo puesto injusticia que fue reparada por el Sr. Guerra y Orbe (RABASF, 1901: 190); evidentemente, con el paso de los años Rada y Delgado había mezclado ligeramente fechas e instituciones -dado que Riaño murió tan sólo una semana antes de estas palabras, es probable que el dato lo sacase de la memoria, en lugar de investigar en archivos- pero la idea general de que Fernández-Guerra y Orbe ayudó a Riaño permaneció en su memoria. Así mismo, parece confirmarse la teoría de que realmente existía un vínculo de amistad entre Fernández-Guerra y Riaño, si bien Aureliano no habría podido hacer mucho debido a que no tenía un puesto desde el que poder impulsar las iniciativas con libertad, tan sólo frenarlas. Dejando aparte la figura de Riaño, es interesante hacer notar la desidia que en el Ministerio de Fomento existía hacia el asunto de la reforma de la Escuela Superior de Diplomática, sin que a ninguno de los ministros precedentes -Antonio de Aguilar y Correa, entre noviembre de 1861 y enero de 1863, y Francisco de Luján Miguel Romero, hasta marzo del 63-pareciese preocuparle mucho el que se apolillase en el cajón del Director General de Instrucción Pública, que era quien debía autorizarlo; aunque se debe reconocer que no era por falta de capacidad de los funcionarios del ministerio, porque en cuanto Huet convence a Moreno López, el Ministro llama al Director, y este llama a su Secretario (que llevaba meses con Riaño metido en su despacho, calentándole la oreja) para que arregle el asunto a todo galope; el Secretario lo remite, el Director da su conformidad y el Ministro lo firma. Y así, en tres o cuatro días - de vacaciones en un balneario-se zanja un asunto que se postergaba desde hacía al menos un año; por un encuentro casual en una estación de tren.

Contra todo pronóstico, en la carta del 19 de julio de $1863^{16}$ Juan Facundo escribe a su hermano Estuve ayer en ministerio y me encontré con la novedad de q ya habia vuelto firmado $p^{r}$ la reyna el decreto arreglando la Escuela. Ya tenemos adelantado este paso. En seguida se mandaron las órdenes á la firma, y no falta mas q a su excelencia no se le antoje encontrar algun pero, sino q antes al contrario las firme y las envie $p^{a}$ que corran. No se encontrarían objeciones, ya que al día siguiente Riaño escribió una carta a su madre -no a Bonifacio- en la que, no sólo le daba las buenas noticias, sino que le copiaba en folio aparte la Real Orden, en contenido y forma, como recuerdo.

Carta del 20 de julio de $1863^{17}$ : Mi queridísima madre. Por la primera vez, después de mas de dos años, escribo á $V$. hoy dandole parte de una noticia que es verdaderamente satisfactoria. Los afanes y los malos ratos que tengo pasados, antes de que llegue este caso, V. y yo los sabemos. Ya dije en mi carta de ayer q habia venido despachado de la Granja el decreto arreglando la Escuela de Diplomática. En el mismo dia que vino se mandaron de aqui las órdenes $p^{a}$ la firma del ministro, y esta mañana cuando fui al ministerio me encontré con q las había devuelto puestas al corriente. Me dieron la mia y aun me

16 Madrid, 19 de julio de 1863. Firmada por Juan Facundo Riaño, dirigida a su hermano Bonifacio Riaño, en Granada.

17 Madrid, 19 de julio de 1863. Firmada por Juan Facundo Riaño, dirigida a su madre, $\mathrm{M}^{\mathrm{a}}$ Dolores Montero, en Granada. 
parecía q era mentira teniendola en la mano. Me nombran catedrático interino, pero me dan todo el sueldo y me han ofrecido tenerme asi todo el tiempo q quiera, $p^{a}$ $q$ mientras tanto me prepare comodamente á entrar en oposición á ella cuando yo lo pida. Ya ve V, q esto no es mal negocio. En categoría y demas puntos estoy considerado lo mismo que los profesores propietarios. Atendiendo á la manera en que está redactado mi nombramiento, y á otras circunstancias q concurren en mí, abrigo la esperanza de q el Consejo de Instrucción Pública declare en propiedad lo q ahora es interino. Cuando regrese $D^{n}$ José Huet, $D^{n}$ Aureliano y demás amigos creo q trabajarán en este sentido. Juan Facundo Riaño quedaba de esta manera confirmado como catedrático -interino aún- de la recién renovada Escuela Superior de Diplomática como profesor de Bellas Artes; es decir, de arqueología.

En este punto es el momento de hacer notar las fechas de las cartas y el Real Decreto. Juan Facundo Riaño y Montero es nombrado «catedrático interino para la asignatura de Historia de las Bellas Artes, creada en la Escuela Superior de Diplomática por Real Decreto de ayer» mediante Real Orden de 16 de julio de 1863; es decir, el Real Decreto lleva fecha de 15 de julio. En la larga carta del 17 de julio, la duodécima, Riaño fechaba en el lunes su partida -el lunes trece- y en el miércoles 15 su regreso y encuentro con Huet y Fernández-Guerra en la estación. Al día siguiente (16) Huet va a ver a Aureliano -supongo que en el Balneario de Cestona, que es donde pasó sus vacaciones- encontrándole a su favor; luego dice que fue una mañana (17) a hablar con Moreno López -a quien convenció- y quien, al día siguiente (18) preguntó varias veces al Director, quien a su vez apremió a Aureliano, etc., etc., etc.; el mismo Riaño dice que se solucionaron los trámites en tres o cuatro días. Y el día 19 ya estaba en Madrid la R.O. firmada por la Reina, que estaba en el Palacio de La Granja, en Segovia. Aún en el caso de que hubiese una ligera exageración, y que la entrevista de Huet con Fernández-Guerra hubiese consistido en que éste le acosó en el tren hasta llegar a Vitoria -a la manera de Riaño en su despacho, pero con el poder de un Senador- no deja de ser de una rapidez insólita incluso hoy en día, sin contar además con que el Real Decreto de reforma de la Escuela Superior de Diplomática lleva fecha de 15; es de suponer que la Reina jugaba con el tiempo a su favor. Por lo que respecta a Riaño, se debe destacar que ya el mismo día en que recoge el nombramiento está pensando en la manera de convertirse en catedrático numerario sin pasar por el examen de oposición que le ofrecen, puesto que él ya había aprobado una; esto era posible porque en la Real Orden se recoge su oposición de 1861 de la siguiente manera: "La Reina (Q.D.G.) se ha dignado nombrar catedrático interino para la asignatura de Historia de las Bellas Artes, creada en la Escuela Superior de Diplomática por Real Decreto de ayer, con sueldo anual de diez y seis mil reales, á Don Juan Facundo Riaño que hizo oposición á igual cátedra en la Escuela Superior de Pintura, Escultura y Grabado y obtuvo primer lugar en la terna" es indudable que en la redacción de la Real Orden está la mano de Aureliano Fernández-Guerra, avezado funcionario que compren- día la importancia de saber redactar en buena forma; gracias a esta acertada redacción de la Real Orden de 16 de julio de 1863, y amparándose en la Ley de Instrucción Pública de 9 de septiembre de 1857, Riaño pudo más adelante solicitar la plaza de catedrático numerario, la cual obtendrá por Real Orden de 30 de marzo de 1864. Fernández-Guerra, por Real Orden de 22 de julio de 1857, fue nombrado vocal secretario de la Junta que tenía que examinar el texto de la Ley de 1857 (Miranda, 2005: 111), por lo que sabía perfectamente lo que se podría o no reclamar en base a esa ley, y la forma en que había que redactar la R.O. para que eso fuese posible. Para terminar, y retomando tan sólo un instante el intranscendente asunto de Cailla-Aureliano, la carta del 21 de julio de $1863^{18}$ se cierra diciendo Riaño: Esta tarde voy á dar una comida en la fonda á los dos auxiliares de Aureliano; porque me han servido mucho en este asunto y siempre es bueno tener á esta gente contenta. Creo que Aureliano tambien se alegrará, porque los quiere mucho. Ninguna referencia a pseudónimos o apellidos, ni a una relación más allá de la estrictamente formal, fruto de su trato al hacer gestiones o preguntar por el estado de su nombramiento, en ausencia de Aureliano Fernández-Guerra.

\section{La Reforma de la Escuela Superior de Diplomática}

No me consta que Pascual de Gayangos tuviese papel alguno en la fase final de la reforma de la Escuela Superior de Diplomática, y mucho menos en la forma en que está redactada la Real Orden; y sin embargo, sí que forma parte de esa reforma de la Escuela Superior de Diplomática. En abril de 1863, la Junta Superior de Archivos y Bibliotecas envió un escrito al Real Consejo de Instrucción instando a que se reformase la Escuela, en él se aludía a la necesidad de establecer estudios de arqueología, e incluso un itinerario académico de arqueología dentro de la Escuela Superior de Diplomática; para ello, proponían dividir la cátedra de Arqueología y Numismática en 5 (Godín, 1995, 40-41). Las asignaturas resultantes serían, según el orden establecido en el escrito, Historia del Arte en los Tiempos Antiguos, Edad Media y Renacimiento: Iluminación de manuscritos, glyptica, pintura, escultura y grabado, Numismática Antigua y de la Edad Media, en especial la de España: "Clasificación y arreglo de monetarios; sistemas métricos y estudios comparativos de los pesos y medidas antiguos con los modernos y del valor relativo de la moneda», Epigrafía griega, romana y de la Edad Media: Antiguas divisiones y límites; conventos jurídicos romanos; colonias, municipios, obispados; reinos; coras o provincias árabes; topónimos, y Arqueología: Indumentaria, panoplia, muebles y utensilios de la Antigüedad y la Edad Media; clasificación y colocación de objetos arqueológicos y artísticos de los museos.

18 Madrid, 21 de julio de 1863. Firmada por Juan Facundo Riaño, dirigida a su hermano Bonifacio Riaño, en Granada. 
Finalmente, las asignaturas resultantes fueron Epigrafia y Geografía antiguas y de la Edad Media, Numismática Antigua y de la Edad Media, en especial la de España: Clasificación y arreglo de monetarios; sistemas métricos y estudios comparativos de los pesos y medidas antiguos con los modernos y del valor relativo de la moneda $\mathrm{e}$ Historia del Arte en los Tiempos Antiguos, Edad Media y Renacimiento. Cerámica, glyptica-Muebles, iluminaciones de manuscritos; clasificación y arreglo de objetos arqueológicos y artísticos en los Museos. Como se ve, la asignatura que absorbió la docencia de la arqueología fue la de Juan Facundo Riaño y Montero.

Al hacer una simple comparación de los Reales Decretos de 7 de octubre de 1856 (por el que se establece la Escuela Diplomática), 31 de mayo de 1860 (por el que se propone su reforma) y de 15 de julio de 1863 (por el que se reorganiza la Escuela Superior de Diplomática), se ve claramente el alcance de las diferentes reformas:

En 1856 se creó la Escuela con las siguientes asignaturas: Paleografía General; Latín; Paleografía Crítica; Clasificación y Arreglo de Archivos y Bibliotecas; Métodos empleados dentro y fuera de España, y parte reglamentaria de los mismos; Historia de España; Elementos de Arqueología y los ejercicios prácticos. Es decir, 7 asignaturas y las prácticas ${ }^{19}$. En 1860 las asignaturas eran 6, más las prácticas: Paleografía General; Latín; Paleografía Crítica; Arqueología y Numismática; Historia de España; Bibliografia; más los ejercicios prácticos. En este año desaparecieron Métodos ... y Elementos de Arqueología; creándose Arqueología y Numismática, la asignatura de Rada y Delgado. En 1863 las asignaturas establecidas fueron: Paleografía General; Latín;, Paleografía Critica; Numismática; Epigrafía y Geografía antiguas y de la Edad Media; Historia de España; Bibliografia; Historia de las Bellas Artes y los ejercicios prácticos. En total 8 asignaturas y las prácticas; dos asignaturas más que en 1860, pero sólo una más que en 1856.
Da la impresión de que, más que dividir la asignatura de Rada y Delgado en tres, volvieron al esquema de 1856 adecuando los nombres al escrito de la Junta Superior de Archivos y Bibliotecas de 1863 e incluyendo para ello, en el Real Decreto de 15 de julio de 1863, el artículo $3^{\circ}$ : La cátedra de Epigrafía y Geografía antiguas se desempeñarán por el Director de la Escuela como obligación aneja á su cargo, creando, eso si, una asignatura completamente nueva, Historia de las Bellas Artes en los tiempos antiguos, Edad Media y Renacimiento, la asignatura de Juan Facundo Riaño y Montero, que casualmente es la única que conserva el nombre sugerido por la Junta a la primera asignatura; aunque recoja el temario de dos, como la de Delgado.

Lo curioso de esa petición de reforma de la Escuela Superior de Diplomática, no es tanto la reorganización de las asignaturas, sino de quién parte la idea; la Junta Superior de Archivos y Bibliotecas, en 1863, estaba formada por el Director General de Instrucción Pública -con cargo de presidente- Pedro Sabau y Larroya, el Director de la Escuela Superior de Diplomática (Antonio Delgado), el Director de la Biblioteca Nacional (Juan Eugenio Hartzenbuch), Pascual de Gayangos y Arce, Cayetano Rossell, Tomás Muñoz y Romero, Manuel González Hernández, José Moreno Nieto y el secretario, Santos de Isasa. De los cinco nombres sin cargo específico, uno es el futuro suegro de Juan Facundo Riaño -Pascual de Gayangos- y el otro -Moreno Nieto- fue su profesor de árabe en Granada, además de amigo personal e integrante de La Cuerda Granadína, donde le apodaban El Maestrico; a lo que se suma la excelente relación de Pascual de Gayangos con Tomás Muñoz, cuyo informe de 1866 -de Gayangos y Muñoz- daría lugar a la creación del Archivo Histórico Nacional.

Desconozco si la plaza como profesor era también buscada por Antonio Delgado, o impuesta, pero creo poder aclarar en parte el porqué abandonó su cátedra en 1865.

\begin{tabular}{|l|l|l|}
\hline \multicolumn{1}{|c|}{1856} & \multicolumn{1}{c|}{1860} & 1863 \\
\hline Paleografía General & Paleografía General & Paleografía General \\
\hline Latín & Latín & Latín \\
\hline Paleografía Crítica & Paleografía Crítica & Paleografía Crítica \\
\hline Clasificación y Arreglo de Archivos y Bibliotecas & Bibliografía & Bibliografía \\
\hline Historia de España & Historia de España & Historia de España \\
\hline Elementos de Arqueología & Arqueología y Numismática & Numismática \\
\hline Métodos empleados dentro y fuera de España... & - & Epigrafía y Geografía antiguas y... \\
\hline - & - & Historia de las Bellas Artes en... \\
\hline Ejercicios Prácticos & Ejercicios Prácticos & Ejercicios Prácticos \\
\hline
\end{tabular}

19 Aunque en 1860 y 1863 los ejercicios prácticos se dividen en tres, uno por curso, en 1856 aparecen como una sola asignatura o apartado; para simplificar se han recogido como uno solo en todos. 
Se ha establecido siempre que hubo de abandonar por problemas de salud (Maier, 2008b: 184), y sin embargo su obra Nuevo Método de clasificación de las nuevas medallas autónomas de España, data de los años 1871-1876; una carta de Riaño fechada a 23 de octubre de $1865^{20}$ abre una nueva posibilidad. Para ponernos en antecedentes, una ola de cólera arrasaba Madrid en 1865 y las clases corrían peligro de suspenderse, Antonio Delgado había salido de la capital para pasar las vacaciones de verano en Bollullos del Condado, Huelva: Dicen que al director de nuestra Escuela, $D^{n}$ Antonio Delgado, le han quitado el destino $p^{r}$ no haberse presentado á principio de curso á cumplir con su obligación. Parece que no tenia licencia, y como tiene esa panza tan hermosa, se habia quedado en su pueblo hasta ver en que paraban estas misas. Sentiré que nos pongan otro peor, aunque me parece cosa dificil; porque $D^{n}$ Antonio a pesar de ser un buen sujeto era el hombre mas tumbon de la tierra, y no se interesaba ni poco ni mucho $p^{r}$ la Escuela, desapego, por otra parte, ya intuido (Mederos, 2010: 170). Naturalmente, esta carta por si sola no puede hacer olvidar que Antonio Delgado falta ya en las navidades de 1864 a las sesiones de la Real Academia de la Historia, y que se reincorpora tan sólo un mes en junio de 1865, para jubilarse a finales de 1865, siendo sustituido en la Escuela Superior de Diplomática ya en diciembre; sin embargo, no son datos que se anulen entre si necesariamente, puesto que Delgado podría haberse visto forzado a dimitir -como una salida honrosa- por haber sido depuesto en la Escuela Superior de Diplomática, o incluso solicitar él mismo -como un favor-que le jubilasen para no perder los privilegios ganados con los años. Revisando la prensa del otoño de 1865 podemos ver que en el periódico La Época, en su edición del 23 de octubre (Época, 1865a, 3), el mismo día de la carta de Riaño, se recoge que El director de la escuela de diplomática ha sido separado del cargo de director y de la cátedra que desempeñaba con arreglo al art. 171 del reglamento de instrucción pública, en razon á no haberse presentado oportunamente en Madrid; el citado artículo dice textualmente: Los Profesores que no se presenten á servir sus cargos en el término que prescriban los Reglamentos, ó permanezcan ausentes del punto de su residencia sin la debida autorización, se entenderá que renuncian sus destinos. Aunque es verdad que en el mismo periódico, una semana después (Época, 1865b: 2), se recoge la concesión de la jubilación á $D$. Antonio Delgado, director de la Escuela superior diplomática. Parece probable que Delgado no dimitiese, sino que tenía miedo del brote de cólera que asolaba Madrid, y le apartaron por no presentarse a dar clase-como punta de iceberg de su despreocupación por los asuntos de la Escuela-, si bien luego consiguió salir con cierto honor del proceso; aunque, al fin y al cabo, sí es cierto que había un problema médico entre las razones, el cólera.

20 Madrid, 23 de octubre de 1865. Firmada por Juan Facundo Riaño, dirigida a su hermano Bonifacio Riaño, en Granada.
Sea como fuere, tiene cierta lógica la desafección de Delgado hacia la Escuela, ya que parece más adecuado como profesor de numismática que de epigrafía -como demuestra su posterior obra- además, Delgado cobraba la nada despreciable suma de 30.000 reales sólo por ser Director, mientras que si lo compaginaba con el puesto de profesor su sueldo aumentaba anualmente en tan sólo en 3.000 -Riaño cobraba 16.000 al año-, por lo que se comprende que no le hiciese gracia el tener que impartir tres lecciones semanales, además de ejercer de Director, y que la asignatura que en principio podría interesarle más, la de numismática, la impartiese otro, seguramente menos preparado que él; a lo que hay que añadir sus obligaciones como Anticuario de la Real Academia de la Historia, que también se resintieron (Mederos, 2010: 172).

\section{Conclusiones}

Desde su creación oficial, en 1856, pasando por la reforma de 1860, hasta la reestructuración de 1863, la Escuela Superior de Diplomática apenas si hacía honor a su primigenia orientación como centro de la enseñanza de la arqueología (Maier, 2008b: 180), como demuestra la petición elevada por la Junta Superior de Archivos y Bibliotecas; con la entrada como profesores de Antonio Delgado y Juan Facundo Riaño, la Escuela se convierte en un centro de alto nivel en cuanto al estudio de la arqueología. Riaño, particularmente, está considerado como uno de los mejores y más preparados profesores de arqueología monumental que ha tenido la Escuela en todos sus años de existencia. La cuestión, en lo que respecta a este estudio, es por qué se reestructuró la Escuela, y por qué en 1863, al poco de haber reorganizado la escuela en 1860 .

Como hemos visto en la carta 12 (17 de julio de 1863), el expediente de reestructuración de la Escuela Superior de Diplomática llevaba un año paralizado en el despacho del Director General de Instrucción Pública, es decir, desde aproximadamente junio de 1862, en todo caso durante el mandato de Antonio de Aguilar y Correa; teniendo en cuenta que antes habría pasado por quien -o quienes- lo plantearon, redactaron y presentaron, es muy posible que el proyecto empezase su andadura varios meses antes, quizás incluso un año, lo que sitúa el planteamiento de reforma a mediados de 1861. Parece inevitable intuir una correspondencia de fechas entre la carta del 11 de agosto de 1861 y el planteamiento de reorganización de la Escuela; y de esta con el nombramiento de Riaño, que como hemos visto corren paralelos.

Volviendo a Juan Facundo Riaño, y a su oposición del 22 de febrero de 1861, veíamos que en la segunda carta (11 de agosto de 1861) rechaza -por medio de su representante-vender el primer puesto de una terna, añadiendo que no quiere destino alguno ni del gobierno ni de los particulares, ¿tiene este ofrecimiento de un destino alguna relación con la plaza de catedrático de la Escuela Superior de Diplomática?; las fechas, desde luego, cuadran en parte. De todas maneras a Riaño no le faltaban contac- 
tos -directos o indirectos- para impulsar una reforma de la Escuela Superior de Diplomática que se ajustase a su perfil y méritos.

Pascual de Gayangos, eminente Individuo de la Real Academia de la Historia, tuvo un papel muy activo en la creación de la Escuela Superior de Diplomática en 1856, por lo que sería una voz a tener en cuenta si plantease que la Escuela debía ser reformada, para mayor gloria de la institución y el país, claro está; la gestión de la Junta Superior de Archivos y Bibliotecas - de la que formaba parte junto con José Moreno Nieto- parece indicar que ayudaron a que la reforma viese la luz, quizás en un intento de desbloquear el expediente, que hacía un año descansaba en el despacho del Director General de Instrucción Pública, a la sazón presidente de dicha Junta, lo que hace imaginar que tuvo lugar una lucha de poder hasta que la petición fue aprobada y elevada al Real Consejo de Instrucción; el hecho de que la presentase Tomás Muñoz y Romero evitaba, seguramente, suspicacias por un posible nepotismo o amiguismo.

También contaba entre sus valedores (como se deduce por la carta de agosto del 61) a Moreno López, y sobre todo a José María Huet, quien es el evidente responsable de que la reforma de la Escuela Superior de Diplomática saliese definitivamente del escollo en el que se encontraba. No debe olvidarse, además, que Aureliano Fernández-Guerra era Secretario de Instrucción Pública, un puesto de cierto poder en el ministerio -el tercero, tras el Ministro y el Director-y, desde el 8 de diciembre de 1855, Individuo de número de la Real Academia de la Historia (como Gayangos) e Individuo de número de la Real Academia Española, desde el 17 de enero de 1856; y ya hemos establecido los numerosos lazos que le unían con Riaño, bien a través de su común emigración desde Granada, bien a través de diversos amigos comunes, como Lafuente Alcántara, los hermanos Oliver Hurtado, Eduardo Saavedra, y algunos más que no nombro porque haría falta citar más cartas y estudios, que no vienen al caso en este momento.

A estos contactos se suma Juan de Dios de la Rada y Delgado; su asignatura Arqueología y Numismática, en principio, habría dado origen a tres asignaturas diferentes, tras la reforma de 1863: Numismática antigua y de la Edad Media, y en especial de España -que siguió impartiendo Rada y Delgado-, Epigrafía y Geografía Antigua y de la Edad Media -que impartió Antonio Delgado-, e Historia de las Bellas Artes en los tiempos antiguos, Edad Media y Renacimiento, a cargo de Juan Facundo Riaño. Juan de Dios de la Rada y Delgado, además de profesor de Derecho de Riaño en Madrid -Riaño hizo el segundo curso de prácticas obligatorias de abogacía en el estudio de Rada y Delgado, en el curso 1860/61- también frecuentaban los mismos círculos de amistades y era amigo personal de Riaño, como dejó claro al hablar en la sede de la Real Academia de Bellas Artes de San Fernando para recordar a Riaño una semana después de su muerte; en esa ocasión, ya que era el único Académico granadino, habló para recordar a su amigo y compañero, de manera que constase en el acta de ese día (RABASF, 1901: 189191), quedando recogido de la siguiente manera por el Secretario General: le conocí, dijo, cuando ambos éramos niños; sus padres y los mios tenian sus casas contiguas en la calle de Abenamar; no es extraño que nuestros juegos y expansiones infantiles corrieran parejas; su recuerdo tan grato para mi, es imperecedero, por ello, sin haber sido nombrado para acompañar el cadáver acudí á rendir el último tributo hasta el postrer momento, al compañero en la Carrera, á mi colega en ambas Academias al Director en fin de esta ilustre asamblea. Por tanto, no sólo no pondría obstáculos al nombramiento de Riaño, sino que lo apoyaría entusiastamente.

Antonio Delgado Hernández no parece tener una especial relación personal con Riaño, pero era ya, desde el 29 de agosto de 1860, Director de la Escuela Superior de Diplomática -sin cargo de profesor-y parece que se aprovechó la reforma para crear una asignatura para él, que al fin y al cabo costaba a las Arcas del Estado tan sólo 3.000 reales, poco en comparación con el gasto de contratar un nuevo catedrático, que costaba al menos 16.000.

Como se ve, el único catedrático que entró realmente nuevo a la Escuela Superior de Diplomática, en 1863, fue Juan Facundo Riaño; de los otros dos profesores, uno ganaba -ya que su asignatura se desprendía de materia lectiva y entraba como compañero un antiguo amigo-, y el otro parece haber sido objeto de un nombramiento no buscado - que le obligaba a dar clases, además de ejercer como Director de la Escuela Superior de Diplomática- y que duró tan sólo dos cursos, por una causa u otra.

No es descabellado, por tanto, establecer que la reforma de la Escuela Superior de Diplomática, del 15 de julio de 1863, es consecuencia directa de que Riaño no obtuviera la plaza de Catedrático de Teoría e Historia de las Bellas Artes en la Escuela Superior de Pintura, Escultura y Grabado de Madrid, en la oposición del 22 de febrero de 1861, y que dicha reorganización se deba exclusivamente a la voluntad de proveer de una plaza de profesor a Juan Facundo Riaño y Montero; siendo muy posible que dicha reestructuración fuese ideada, en un primer momento, desde el Ministerio de Fomento por Aureliano Fernández-Guerra, apoyada -desde la misma Escuela-por Rada y Delgado, y desde la Junta Superior de Archivos y Bibliotecas por Pascual de Gayangos y José Moreno Nieto, e impulsada en el momento oportuno por José María Huet y Allier - deus ex máchina-gracias a su amistad con Manuel Moreno López, el Ministro de Fomento, quien sólo permanecería en el puesto entre el 3 de marzo y el 4 de agosto de 1863 , el tiempo justo para nombrar Catedrático a Riaño.

Afortunadamente para la Escuela Superior de Diplomática, y para los alumnos que pasaron por sus aulas, Riaño - capaz de superar al mismo Manuel de Assas en las oposiciones de 1861, y ser considerado digno de pertenecer al Instituto Arqueológico Imperial Alemán de Berlín y Roma, la más importante institución europea dedicada a la investigación de la arqueología en ese momento- resultó ser un excelente profesor, que destacaba, cuando sólo con- 
taba con un simple Bachillerato en Filosofía y Letras (lo mismo que exigían para ser admitido como alumno en la Escuela Superior de Diplomática) por sus conocimientos de arqueología y filología.

\section{BibLIOGRAFÍA}

Almagro Gorbea, M. (2002): “La Real Academia Española de la Historia". Historiografía de la Arqueología Española. Las Instituciones. Museo de San Isidro. Madrid: 47-81.

Álvarez Ramos, M.A. y Álvarez Millán, C. (2007): Los viajes literarios de Pascual de Gayangos (1850-1857) y el origen de la archivística española moderna. Colección Estudios Árabes e Islámicos: Monografías 12. CSIC. Madrid.

Ballart Hernández, J. y Juan i Tresserras, J. (2008): Gestión del patrimonio cultural. Ariel. Barcelona.

Berlanga Palomo, MJJ. (2001): "La enseñanza de la arqueología en el siglo XIX: de las cátedras de Castellanos de Losada a la introducción en los estudios universitarios". Anales de Arqueología Cordobesa, 12: 13-33.

Blech, M. (2002): "La aportación de los arqueólogos alemanes a la arqueología española". Historiografía de la Arqueología Española. Las Instituciones. Museo de San Isidro. Madrid: 83-117.

Época, La. (1865a): La Época, 23-10-1865, n. ${ }^{\circ} 5.426$. Madrid.

Época, La. (1865b): La Época, 30-10-1865, n. ${ }^{\circ} 5.432$. Madrid.

ESD (1865): Reglamento de la Escuela Superior de Diplomática. Ribadeneyra (Imp.), Madrid.

Exp.1 (1863): Expediente de Licenciatura en Filosofía y Letras de Juan Facundo Riaño de la Universidad Literaria de Granada, 761-129, n ${ }^{\circ}$ 1, f.40, 1193. Archivo Universitario de Granada.

Gallego Roca, M. (1991): La Cuerda granadina, una sociedad literaria del Postromanticismo. Comares. Granada.

García Medina, A. (2007): "El archivo de la Escuela Superior de Diplomática". Revista General de Información y Documentación, 17 (1): 213-226.

Godín Gómez, A. (1995): “La Escuela Superior de Diplomática y la formación de los archiveros, bibliotecarios y arqueólogos en el siglo XIX". Boletín de la ANABAD, 45 (3): 33-50.

Gómez Álvarez, J. (2007): “Fuentes iconográficas del imaginario histórico-artístico de los estudiantes de la enseñanza media española”. Toleitola, 9: 19-20.

González Reyero, S. (2007): La fotografía en la Arqueología española (1860-1960): 100 años de discurso arqueológico a través de la imagen. Real Academia de la Historia. Madrid.

López-Ocón Cabrera, L. (2010): “El papel de Juan Facundo Riaño como inductor del proyecto cultural del Catálogo Monumental de España". Catálogo Monumental de España (1900-1961). CSIC. Madrid: 51-73.
Macarrón, A. y González Mozo, A. (2007): La conservación y la restauración en el siglo XX. Tecnos. Madrid.

Maier Allende, J. (2008a): Noticias de Antigüedades de las Actas de Sesiones de la Real Academia de la Historia (1834-1874). Real Academia de la Historia. Madrid.

Maier Allende, J. (2008b): "La enseñanza de la Arqueología y sus maestros en la Escuela Superior de Diplomática". Revista General de Información y Documentación 18 (1): 173-189.

Mederos Martín, A. (2010): “Análisis de una decadencia. La arqueología española del siglo XIX: El impulso isabelino (1830-1867)". Cuadernos de Prehistoria y Arqueología de la Universidad Autónoma de Madrid, 36: 159-216. DOI: http://dx.doi.org/10.15366/ cupauam2010.36.008

Miranda Valdés, J. (2005): Aureliano Fernández-Guerra y Orbe (1816-1894) un romántico, escritor y anticuario. Real Academia de la Historia. Madrid.

Oliver Hurtado, J. y Oliver Hurtado, M. (1861): Munda Pompeiana. M Galiano Impresor. Madrid.

Pasamar, G.V. y Peiró, I. (1996): La Escuela Superior de Diplomática (Los archiveros en la historiografía española contemporánea). ANABAD. Madrid.

RABASF (1901): Libro de Actas de Sesiones de la Real Academia de Bellas Artes de San Fernando. Año 1901. Signatura 3-104.

Riaño y Montero, J.F. (1869): “La crónica general de D. Alfonso el Sabio, elementos que concurren a la cultura de la época". Discursos leídos ante la Academia de la Historia, en la recepción pública de Don Juan Facundo Riaño, el día 10 de octubre de 1869. Real Academia de la Historia. Madrid.

Romero Recio, M. (2005): "La Biblioteca de la Escuela Superior de Diplomática: la presencia de la Historia Antigua en la enseñanza española del siglo XIX a través de sus fondos". Gerión ,23 (1): 345-370.

Torres Aguilar-Amat, R. (1882): "Elogio de Don José Moreno Nieto". Boletín de la Sociedad Geográfica de Madrid, 12 (6): 476-494.

Epistolario inédito (Hispanic Society of America, Nueva York y descendientes de Juan Facundo Riaño, Granada)

Carta 1: Madrid, 1 de abril de 1861. Firmada con el pseudónimo de Raya (a quien identifico como Mariano Vázquez Gómez), dirigida a Aguilar, posiblemente Antonio Almendros Aguilar; ambos miembros de La Cuerda Granadina y amigos de Riaño.

Carta 2: Madrid, 11 de agosto de 1861. Firmada con las iniciales CyA o CyS (a quien identifico como José de Castro y Serrano, de La Cuerda Granadina), dirigida a Emilio Lafuente Alcántara, amigo y compañero de Riaño en las clases de árabe de José Moreno Nieto en la Universidad Literaria de Granada.

Carta 3: Madrid, 7 de octubre de 1861. Firmada por Gregorio Cruzada Villaamil (protector de la Colonia Granadina/La Cuerda Granadina en Madrid) e 
Ivón, apodo de José Fernández Jiménez en La Cuerda Granadina; dirigida a Juan Facundo Riaño, en Granada.

Carta 4: Madrid, 14 de abril de 1863. Firmada por Juan Facundo Riaño, dirigida a su hermano Bonifacio Riaño, en Granada.

Carta 5: Madrid, 20 de abril de 1863. Firmada por Juan Facundo Riaño, dirigida a su hermano Bonifacio Riaño, en Granada.

Carta 6: Madrid, 22 de abril de 1863. Firmada por Juan Facundo Riaño, dirigida a su hermano Bonifacio Riaño, en Granada.

Carta 7: Madrid, 6 de mayo de 1863. Firmada por Juan Facundo Riaño, dirigida a su hermano Bonifacio Riaño, en Granada.

Carta 8: Madrid, 8 de mayo de 1863. Firmada por Juan Facundo Riaño, dirigida a su hermano Bonifacio Riaño, en Granada.

Carta 9: Madrid, 11 de junio de 1863. Firmada por Juan Facundo Riaño, dirigida a su hermano Bonifacio Riaño, en Granada.
Carta 10: Madrid, 9 de julio de 1863. Firmada por Juan Facundo Riaño, dirigida a su hermano Bonifacio Riaño, en Granada.

Carta 11: Madrid, 13 de julio de 1863. Firmada por Juan Facundo Riaño, dirigida a su hermano Bonifacio Riaño, en Granada.

Carta 12: Madrid, 17 de julio de 1863. Firmada por Juan Facundo Riaño, dirigida a su hermano Bonifacio Riaño, en Granada.

Carta 13: Madrid, 19 de julio de 1863. Firmada por Juan Facundo Riaño, dirigida a su hermano Bonifacio Riaño, en Granada.

Carta 14: Madrid, 19 de julio de 1863. Firmada por Juan Facundo Riaño, dirigida a su madre, $\mathrm{M}^{\mathrm{a}}$ Dolores Montero, en Granada.

Carta 15: Madrid, 21 de julio de 1863. Firmada por Juan Facundo Riaño, dirigida a su hermano Bonifacio Riaño, en Granada.

Carta 16: Madrid, 23 de octubre de 1865. Firmada por Juan Facundo Riaño, dirigida a su hermano Bonifacio Riaño, en Granada. 
